\title{
Viewpoints of Family Caregivers about Posttraumatic Growth in Cancer Patients
}

\author{
Hale Tahory ${ }^{1}$, Robab Mohammadian ${ }^{2}$, Azad Rahmani*, Alehe Seyedrasooli ${ }^{4}$, \\ Sima Lackdezajy ${ }^{4}$, Mehdi Heidarzadeh ${ }^{5}$
}

\begin{abstract}
Background: There is little information about the objectivity of posttraumatic growth experienced by cancer patients. So, the aim of present study was to investigate the viewpoints of family caregivers regarding posttraumatic growth in cancer patients. Materials and Methods: This descriptive study was conducted in one referral medical center in East Azerbaijan Province in northwest of Iran. 120 primary family caregivers of cancer patients participated with a convenience sampling method. The Posttraumatic Growth Inventory (PTGI) and Perception about Prognosis Scale (PPS) were applied for data collection with analysis performed using SPSS statistical software. Results: Family caregivers believed that their patients had a good prognosis (score 3.95 from 5). The total score of PTGI was $60.7(\mathrm{SD}=18.8)$ that indicates a moderate level of growth as reported by family caregivers. Conclusions: Family caregivers of cancer patients have incorrect viewpoints about the prognosis of their patients and reported moderate levels of growth. These findings showed that posttraumatic growth among cancer patients is an objective phenomenon.
\end{abstract}

Keywords: Cancer patients - posttraumatic growth - prognosis - family caregivers - Iran

Asian Pac J Cancer Prev, 17 (2), 755-758

\section{Introduction}

The diagnosis of malignant tumors has a profound impact on all aspect of patients' life from the initial diagnosis until late stages of the disease (Schroevers et al., 2010). This diagnosis may lead to many negative consequences such as: anxiety, depression (Morris et al., 2012a), fear of cancer recurrence (Aghdam et al., 2014), fear about feature and prognosis of disease (Seyedrasooli et al., 2014), physical limitation (Abdollahzadeh et al., 2014), and financial distress (Fathollahzade et al., 2015).

For many years, trauma was defined only a damaging experience; however, recent literature indicates that trauma can also lead to positive changes that referred as posttraumatic growth (Rahmani et al., 2012). Posttraumatic growth is defined as a positive psychological change that occurs following a meaningfully challenging or traumatic life event and is often characterized by an increased appreciating for life, better interpersonal relationships, personal strength, recognition of new possibilities, and spiritual development (Crawford et al., 2015)

There are many studies investigated posttraumatic growth level among cancer patients worldwide. The result of some studies in United States (Danhauer et al., 2013), Canada (Crawford et al., 2015), Australia (Morris et al., 2012b), and Hungary (Tanyi et al., 2015) showed moderate level of posttraumatic growth for cancer patients. On the other hand, the results of some studies showed moderate to high level of posttraumatic growth among Iranian cancer patients (Rahmani et al., 2012; Bahrami et al., 2015; Mehrabi et al., 2015).

It should be noted that in most of previous studies the viewpoint of cancer patients about posttraumatic growth in themselves was investigated (Parikh et al., 2015; Shand et al., 2015) and this idea has been proposed that the viewpoint of patients in this regards may be incorrect and subjective (Sumalla et al., 2009). So, there is a need for assessment of such growth from the viewpoints of others who are living with patients. In wide review of literature, we found no studies investigated the experiences of family caregivers of cancer patients regarding posttraumatic growth in their patients. So, the aim of present study was to investigate the viewpoints of family caregivers regarding posttraumatic growth in cancer patients.

\section{Materials and Methods}

This descriptive study was conducted in in-patient wards and out-patient clinic in one referral medical center in East Azerbaijan Province in northwest of Iran. The

${ }^{1}$ Medical \&Surgical Department, ${ }^{3}$ Hematology and Oncology Research Center, ${ }^{4}$ Medical Surgical Department, Nursing and Midwifery Faculty, Tabriz. University of Medical Sciences, Tabriz, ${ }^{2}$ Department of Nursing, Islamic Azad University, Maraghe Branch, Maraghe, ${ }^{5}$ Medical Surgical Department, Nursing and Midwifery Faculty, Ardabil University of Medical Sciences, Ardabil, Iran*For correspondence: azad.rahmani@yahoo.com 
participation of present study was the family caregivers of cancer patients with the following inclusion criteria: having at least 18 years old; having final diagnosis of cancer in one of main family members; being the primary caregiver of patient; at least six month passed since awareness of cancer patients and family caregivers regarding exact diagnosis; and mentally and physically able to participate in the study. The sample size of 115 primary caregivers was calculated after conduction a pilot study on 15 potential participants. In this regards, 130 participants was invited to the study and finally the data of 120 ones included in the study with convenience sampling method (participation rate $=92 \%$ ).

The instrument used in present study consisted of three parts. The first part was a demographic checklist that investigated some information about family caregivers and their patients. The second part was a Posttraumatic Growth Inventory (PTGI), a 21-item questionnaire invited to examine positive growth reported by individuals who have experienced stressful events. The PTGI consists of five subscales including: relating to others (7 items), new possibilities ( 5 items), personal strength ( 4 items), appreciation of life (3 items) and spiritual changes (2 items). The items of PTGI was based 6-point Likert scale ranging from 0 (I did not experience this change as a result of cancer) to 5 (I strongly experienced this change as a result of cancer). The total score of PTGI is ranged between 0-105 (Tedeschi and Calhoun, 1996). Higher score indicates higher levels of positive growth. This instrument was used in previous Iranian studies (Seidmahmoodi et al., 2011; Rahmani et al., 2012). The third part was a Perception about Prognosis Scale (PPS) that designed based on previous studies (Seyedrasooli et al., 2014; Seyedrasooly et al., 2014). This scale consist of three items regarding based on 5-itesm Likert scale from very bad to very good that receive 1 to 5 score respectively. The total score was from 3 to 15 and higher score indicates more positive perception about the prognosis of the disease.

For using in present study, a Persian version of PTGI was developed from the original English version by translation and back-translation procedures. Then the parallel form of the questionnaire was designed for the primary family caregivers of cancer patients. In this instrument the caregivers were asked about their observation about posttraumatic growth in their cancer patients. Then the validity of the final questionnaires was determined by content validity by 10 academic staff from Tabriz University of Medical Sciences. Afterthought, the questionnaire was pilot-tested in a sample of 15 potential participants and sowed a high levels of internal consistency (Cronbach alpha $>0.93$ ).
Before data collection, the study proposal was approved by Regional Ethics Committee at Tabriz University of Medical Sciences. Then, one of researchers was referred to study setting and invited potential participants to the study after receiving signed informed consent. Then, willing participants were asked to fill out questionnaire by private interview with one of refreshers. Data collection lasted from February to June in 2015.

Data analysis was performed using SPSS statistical software (version 13. SPSS, Inc., Chicago, IL). Descriptive statistic was used to describe some characteristics of primary caregivers and their patients, the perception about prognosis and PTGI scores.

\section{Results}

Some characteristics of family caregivers and their patients are reported in Table 1 . As shown, most of caregivers were female, married, educated at diploma level, and be a child of patients. In addition, most of patients were male, educated at diploma level and diagnosed with hematologic cancers. Also, the mean age

Table 1. Demographic Characteristics of Participants

\begin{tabular}{|c|c|c|}
\hline Variable & Frequency & Percent \\
\hline \multicolumn{3}{|l|}{ Sex of caregiver } \\
\hline Male & 58 & 48.3 \\
\hline Female & 62 & 51.7 \\
\hline \multicolumn{3}{|l|}{ Education of caregiver } \\
\hline Illiterate & 9 & 7.5 \\
\hline Primary & 35 & 29.2 \\
\hline Diploma & 48 & 40 \\
\hline University & 27 & 22.5 \\
\hline \multicolumn{3}{|l|}{ Marital status } \\
\hline Married & 104 & 86.7 \\
\hline Single & 16 & 13.3 \\
\hline \multicolumn{3}{|l|}{ Type of relationship with patient } \\
\hline Child of patient & 38 & 31.7 \\
\hline Spouse of patient & 33 & 27.5 \\
\hline Parent of patient & 15 & 12.5 \\
\hline Brother or sister of patient & 34 & 28.3 \\
\hline \multicolumn{3}{|l|}{ Sex of patient } \\
\hline Male & 61 & 50.8 \\
\hline Female & 59 & 49.2 \\
\hline Illiterate & 21 & 17.5 \\
\hline \multicolumn{3}{|l|}{ Education of patient } \\
\hline Primary & 48 & 40 \\
\hline Diploma & 32 & 26.7 \\
\hline University & 19 & 15.8 \\
\hline Breast & 15 & 12.5 \\
\hline \multicolumn{3}{|l|}{ Type of cancer } \\
\hline Gastro-intestinal & 35 & 29.2 \\
\hline Hematologic & 44 & 36.7 \\
\hline Other & 26 & 21.7 \\
\hline
\end{tabular}

Table 2. Participants Response to items of Perception about Prognosis Scale

\begin{tabular}{|c|c|c|c|c|c|c|}
\hline Items & $\begin{array}{c}\text { Very bad } \\
\mathrm{N}(\%)\end{array}$ & $\begin{array}{c}\text { Bad } \\
\mathrm{N}(\%)\end{array}$ & $\begin{array}{l}\text { Medium } \\
\mathrm{N}(\%)\end{array}$ & $\begin{array}{l}\text { Good } \\
\text { N (\%) }\end{array}$ & $\begin{array}{l}\text { Very good } \\
\text { N }(\%)\end{array}$ & Mean (SD) \\
\hline Drug impact on the treatment & $4(3.3)$ & $4(3.3)$ & $28(23.3)$ & $53(44.2)$ & $31(25.8)$ & $3.85(0.94)$ \\
\hline Having a normal lifetime & $4(3.3)$ & $6(5)$ & $21(17.5)$ & $44(36.7)$ & $45(37.5)$ & $4(1.02)$ \\
\hline Illness being curable & $5(4.2)$ & $6(5)$ & $18(15)$ & $43(35.8)$ & $48(40)$ & $4.03(1.06)$ \\
\hline
\end{tabular}


Table 3. Participants Response to items of Posttraumatic Growth Inventory

\begin{tabular}{lll}
\hline Items & Mean & SD \\
\hline my priorities about what is important in life & 2.2 & 1.73 \\
an appreciation for the value of my own life & 3.59 & 1.52 \\
I developed new interests & 1.68 & 1.67 \\
a feeling of self-reliance & 2.53 & 1.78 \\
a better understanding of spiritual matters & 3.38 & 1.55 \\
knowing that I can count on people in times of trouble & 3.47 & 1.58 \\
I established a new path for my life & 1.83 & 1.63 \\
a sense of closeness with others & 2.32 & 1.77 \\
a willingness to express my emotions & 2.81 & 1.72 \\
knowing I can handle difficulties & 2.08 & 1.64 \\
I'm able to do better things with my life & 2.44 & 1.64 \\
being able to accept the way things work out & 2.8 & 1.79 \\
appreciating each day & 3.64 & 1.57 \\
new opportunities are available which wouldn't have been otherwise & 1.9 & 1.57 \\
having compassion for others & 3.48 & 1.61 \\
putting effort into my relationships & 3.31 & 1.54 \\
I'm more likely to try to change things which need changing & 2.91 & 1.66 \\
I have a stronger religious faith & 3.55 & 1.73 \\
I discovered that I am stronger than I thought I was & 3.18 & 1.66 \\
I learned a great deal about how wonderful people are & 3.25 & 1.69 \\
I accept needing others & 4.38 & 1.05 \\
\hline
\end{tabular}

of caregivers and patients were 39.71 and 46.01 years respectively. In addition, the mean of time passed since diagnosis was 31.45 month.

The responses of participants to all items of Perception about Prognosis Scale (PPS) are reported in Table 2. As evident in this Table, the mean score of participants in all three items were more than 3.85 (from 5) that indicated good viewpoint about prognosis. The mean score of partcipants in PPS was 3.95 ( $\mathrm{SD}=0.86)$.

The responses of family caregivers to all items of Posttraumatic Growth Inventory are reported in Table 3 . The total score of PTGI was $60.72(\mathrm{SD}=18.75)$ that indicates moderate level of growth as reported by family caregivers.

\section{Discussion}

The aim of present study was to investigate the viewpoints of family caregivers regarding posttraumatic growth in cancer patients. Based on our knowledge, this is the first article investigated the viewpoint of family caregivers of cancer patients regarding posttraumatic growth in cancer patients.

One finding of present study is that family members of cancer patients consider good prognosis for their patients (mean score of 4 from 5). There are some Iranian studies that reported Iranian cancer patients believed that the prognosis of their disease is good (Seyedrasooli et al., 2014; Seyedrasooly et al., 2014). But, this study is the first that reported such finding among family members of cancer patients. This issue is not specific to Iranian cancer patients and results of some studies in Western countries (Sanatani et al., 2008; Eliott and Olver, 2009) and non-western countries (Banning and Gumley, 2012) have shown that a major percentage of cancer patients in these countries do not have the right information of their prognosis.

The result of present study showed that family caregivers of cancer patients reported moderate level of posttraumatic growth in their patients (mean of 61 in PTGI). There are some studies that investigated the levels of posttraumatic growth among family members of cancer patients. These studies showed that family members of cancer patients experienced some levels of posttraumatic growth (Kazak et al., 2004; Kim et al., 2013; Han et al., 2015). But, we found no studies investigated the posttraumatic growth among cancer patients as reported by their family caregivers. Although, in some studies the posttraumatic level of Iranian cancer patients is reported. As an example, the result of a study by Rahmani et al, (2012) showed that Iranian cancer patients reported high levels of posttraumatic growth and their score on PTGI was 76 (Rahmani et al., 2012). Similarly, the results of another study by Heidarzade et al. (2014) showed high level of posttraumatic growth among Iranian cancer pates as evident by score of 68 in PTGI (Heidarzadeh et al., 2014). So, we may conclude that the posttraumatic growth level as reported by Iranian cancer patients is more that this level as reported by family members of cancer patients.

The results of present study have some clinical implication. First, the results showed that family caregivers of cancer patients have incorrect viewpoint about the prognosis of their patients. This finding is unexpected because we know that most of Iranian oncologists, or physicians with other specialties, disclose cancer diagnosis and prognosis to family members of cancer patients. So, understanding the causes of the occurrence of this phenomenon requires further studies. Second, although family members reported less posttraumatic growth in cancer patients as compared with patients, but they reported moderate levels of growth in their patients. This finding confirms that posttraumatic growth reported by cancer patients is an objective phenomenon. So, health care personnel may use this strength as a positive asset of patients in establishing and delivery of health care they provided for patients. 
The results of present study have some limitations. First, this study was conducted in one referral hospital in northwest of Iran and don not representing all cultural and religious diversity in Iran. Second, in this study only the viewpoint of family caregivers of cancer patients regarding posttraumatic growth in cancer patients was investigated and this viewpoint was compared with the results of previous studies regarding viewpoint of patients.

\section{Acknowledgements}

This article is a part of Master of Science thesis in nursing and midwifery faculty of Tabriz University of Medical Sciences. Authors appreciate all family members of cancer patients who participated in this study.

\section{References}

Abdollahzadeh F, Moradi N, Pakpour V, et al (2014). Un-met supportive care needs of Iranian breast cancer patients. Asian Pac J Cancer Prev, 15, 3933-8.

Aghdam AM, Rahmani A, Nejad ZK, et al (2014). Fear of cancer recurrence and its predictive factors among iranian cancer patients. Indian J Palliat Care, 20, 128-33.

Bahrami M, Taleghani F, Loripoor M, et al (2015). Positive changes after breast cancer: A qualitative study. J Educ Health Promot, 4, 55.

Banning M, Gumley VA (2012). Clinical nurses' expressions of the emotions related to caring and coping with cancer patients in Pakistan: a qualitative study. Eur J Cancer Care, 21, 800-8.

Crawford JJ, Vallance JK, Holt NL, et al (2015). Associations between exercise and posttraumatic growth in gynecologic cancer survivors. Support Care Cancer, 23, 705-14.

Danhauer SC, Russell GB, Tedeschi RG, et al (2013). A longitudinal investigation of posttraumatic growth in adult patients undergoing treatment for acute leukemia. J Clin Psychol Med Settings, 20, 13-24.

Eliott JA, Olver IN (2009). Hope, life, and death: a qualitative analysis of dying cancer patients' talk about hope. Death Stud, 33, 609-38.

Fathollahzade A, Rahmani A, Dadashzadeh A, et al (2015). Financial distress and its predicting factors among iranian cancer patients. Asian Pac J Cancer Prev, 16, 1621-5.

Han JH, Han SH, Lee MS, et al (2015). Primary Caregivers' Support for Female Family Members With Breast or Gynecologic Cancer. Cancer Nurs. [Epub ahead of print]

Heidarzadeh M, Rassouli M, Shahbolaghi FM, et al (2014). Posttraumatic growth and its dimensions in patients with cancer. Middle East J Cancer, 5, 23-9.

Kazak AE, Alderfer M, Rourke MT, et al (2004). Posttraumatic stress disorder (PTSD) and posttraumatic stress symptoms (PTSS) in families of adolescent childhood cancer survivors. J Pediatr Psychol, 29, 211-9.

Kim Y, Carver CS, Schulz R, et al (2013). Finding benefit in bereavement among family cancer caregivers. $J$ Palliat Med, 16, 1040-7.

Mehrabi E, Hajian S, Simbar M, et al (2015). Post-traumatic growth: a qualitative analysis of experiences regarding positive psychological changes among Iranian women with breast cancer. Electron Physician, 7, 1239-46.

Morris BA, Chambers SK, Campbell M, et al (2012a). Motorcycles and breast cancer: the influence of peer support and challenge on distress and posttraumatic growth. Support Care Cancer, 20, 1849-58.
Morris BA, Shakespeare-Finch J, Scott JL (2012b). Posttraumatic growth after cancer: the importance of health-related benefits and newfound compassion for others. Support Care Cancer, 20, 749-56.

Parikh D, De Ieso P, Garvey G, et al (2015). Post-traumatic stress disorder and post-traumatic growth in breast cancer patients-a systematic review. Asian Pac J Cancer Prev, 16, 641-6.

Rahmani A, Mohammadian R, Ferguson C, et al (2012). Posttraumatic growth in Iranian cancer patients. Indian $J$ Cancer, 49, 287-92.

Sanatani M, Schreier G, Stitt L (2008). Level and direction of hope in cancer patients: an exploratory longitudinal study. Support Care Cancer, 16, 493-9.

Schroevers MJ, Helgeson VS, Sanderman R, et al (2010). Type of social support matters for prediction of posttraumatic growth among cancer survivors. Psychooncol, 19, 46-53.

Seidmahmoodi J, Rahimi C, Mohamadi N (2011). Resiliency and religious orientation: factors contributing to posttraumatic growth in Iranian subjects. Iran J Psychiatry, 6, 145-50.

Seyedrasooli A, Rahmani A, Howard F, et al (2014). Iranian cancer patient perceptions of prognosis and the relationship to hope. Asian Pac J Cancer Prev, 15, 6205-10.

Seyedrasooly A, Rahmani A, Zamanzadeh V, et al (2014). Association between Perception of Prognosis and Spiritual Well-being among cancer Patients. J Caring Sci, 3, 47-55.

Shand LK, Cowlishaw S, Brooker JE, et al (2015). Correlates of post-traumatic stress symptoms and growth in cancer patients: a systematic review and meta-analysis. Psychooncol, 24, 624-34.

Sumalla EC, Ochoa C, Blanco I (2009). Posttraumatic growth in cancer: reality or illusion? Clin Psychol Rev, 29, 24-33.

Tanyi Z, Szluha K, Nemes L, et al (2015). Positive consequences of cancer: exploring relationships among posttraumatic growth, adult attachment, and quality of life. Tumori, 101, 223-31.

Tedeschi RG, Calhoun LG (1996). The posttraumatic growth inventory: measuring the positive legacy of trauma.J Trauma Stress, 9, 455-71. 